\title{
BREVES NOTAS ACERCA DE PACHACAMAC
}

Arturo Jiménez Borja y Alberto Bueno Mendoza

Pachacamac ofrece una larga historia de ocupación humana. La más antigua, lo constituyen unas gentes portadoras del tipo de materiales culturales que denominamos Maranga. Estas gentes hacían edificios ceremoniales complicados, la base de adobitos pequeños modelados a mano y dispuestos en forma vertical para formar muros. Frente a las instalaciones del Museo de Sitio y Cafetería, se excavó en 1964-65, una de las varias estructuras Maranga que hay en el sitio. El resultado fue la aparición de un templete con un recinto rectangular central, que presentaba una especie de terraza, donde estaban implantados unos maderos, quizás para sostener una ramada. Este recinto central se comunicaba con el exterior por un pequeño vano que fungía de puerta. Le rodean depósitos hacia el Este y hacia el Oeste un patio central dividido por un muro central. Uno de los espacios presenta una doble hilera de maderos implantados en el piso, colocados uno frente al otro; éstos también deben haber sostenido un techo. Los enlucidos de muros y pisos son magníficos, conservándose un buen ejemplo de ellos. La cerámica recuperada presenta una forma novedosa y también las ya conocidas en otros centros del mismo estilo en el Valle del Rímac: "San Marcos", "Juliana", "Catalina Huanta", "Cajamarquilla I", etc. La decoración tricolor y tonalidades del rojo, negro y blanco son características de los motivos pictóricos, diseñados geométricamente en superficies externas y el exterior de platos abiertos de bordes simples. El edificio fue excavado por "pisos", hallando durante los trabajos seis "pisos" de ocupación sucesiva, que fueron considerados como estratos. Cada uno de ellos arrojaron a su tiempo una fase estilística de cerámica. Así tenemos, cerámica Maranga de este edificio, desde la fase 4 hasta la 9, teniendo como referencia la seriación hecha por Thomas Carl Patterson, que publica en su libro "Pattern and Process in the Early Intermediate Period Pottery of the Central COSAT of Peru", 1966. Hemos utilizado la cerámica para tratar de fechar relativamente el edificio. Así, consideramos que la gente Maranga ocupó por primera vez el estilo hacia el $400 \mathrm{~d}$. C. y se mantuvo hasta más o menos el 800 d.C., en que empezaron a llegar influencias extrañas al sitio y a la costa central en general. En que empezaban los tiempos Wari en la costa central lo que trataremos más adelante.

Otros sectores del sitio con ocupación Maranga lo hemos detectado debajo de Mamacuna (edificio más tardío); en Urpi Wachak, estructura arquitectónica circular completamente sepultada en la actualidad. También pensamos que los Maranga deben haber empezado a construir el templo redondo preinca de Pachacamac, se le siguió construyendo durante el efímero periodo de la vigencia Wari y seguramente fue completado en el periodo Reynos y Confederaciones, Futuras exploraciones nos permitirán comprobar estas hipótesis, que ahora son sólo variables de trabajo. 
Habíamos dicho líneas atrás que la gente Wari empieza su influencia en el sitio a partir del 800 d.C. Esta influencia debe haberse ejercido a través de la gente maranga, desde el sitio de Cajamarquilla ubicado en el valle del Rímac; inferimos esto debido a que la cerámica Maranga del valle del Rímac, acusa contactos con la Sierra Central desde los tiempos pre-Wari. El comercio inter-regional por otro lado, se acrecentó enormemente durante la expansión Wari y Cajamarquilla era colonia Wari en la Costa Central a partir del 800 d.C. Los comerciantes Wari de Cajamarquilla habrían venido al Valle de Lurín fomentando su comercio y como la gente Maranga habitaba estos valles, tuvieron necesariamente que verse impactados y poco a poco absorbidos por las ideas y modos culturales de esta corriente serrana. Desde el punto de vista arqueológico la presencia Wari en Pachacamac sólo está presente en tumbas que excavó Uhle al pie del templo, preinca de Pachacamac. Estas tumbas estaban ubicadas sobre otras anteriores conteniendo muertos y materiales Maranga que al arqueólogo alemán llamó Proto Lima. Justamente el hecho de que el cementerio más viejo de todo el sitio contenga esta superposición de tumbas, hace sospechar que por lo menos una parte de la edificación se haya empezado desde tiempos Maranga. Este edificio ceremonial servia seguramente de elemento gregario en derredor del cual se congregaba la gente Maranga del valle. Los comerciantes Wari apreciarían su importancia y consideraron lugar apropiado para sus enterramientos. La gente Wari no debe haber hecho edificios en Pachacamac, sino más bien en Cajamarquilla, que era su centro. De este modo vemos claros dos cosas: por un lado, la ceremonialidad ha sido una característica propia del sitio desde los primeros tiempos de su ocupación y por otro, el auge constructivo de estructuras arquitectónicas empezó bien tarde.

La vigencia Wari en Pachacamac debe haberse diluido al mismo tiempo que se abandonaba Cajamarquilla y toda esta gente empezó de nuevo a acomodarse en lugares aptos para la vivienda, el trabajo y el aprovechamiento de recursos naturales. Desocupada Cajamarquilla la gente empezó a establecerse en "pequeños lugarejos de corta vecindad": nacieron entonces Campoy, Puruchuco, Pariachi, Ceres, Orión, Gloria, etc. todos seguramente por el 1300 d.C. En los que respecta a Pachacamac, es el tiempo que la burocracia dirigente del culto en el templo inconcluso de Pachacamac, debe haber empezado a predicar la necesidad de continuar la obra, a la vez que propalaban las seguridades que otorgaban para su prosecución. Para esto recurrieron a la invención de la deidad, basándose en un "epígono" de antiguos cultos andinos, pero con atributos novedosos. Surgió así el culto al ídolo de Pachacamac, los sacerdotes, hombres que a lo largo de toda la humanidad se autotitulan intérpretes de la voluntad de los dioses, lo rodearon del misterio, atributos y símbolos necesarios para su omnipotente funcionamiento y autoridad. El ídolo es de madera (¿llonque?); mide 2.10 metros de altura. En algunas figuras de los motivos representados puede verse su antigua filiación a los tiempos Wari, pero en forma reinterpretada. Su nombre preincaico será "IRMA", deidad tutelar del valle de Irma. Pachacamac, es su nombre inca en quechua, y se lo pusieron al incluirlo en su relación de dioses. Ahora se le llama con su nombre quechua, así como también a la ciudad que ahora desconocemos su nombre original.

Los tiempos post Wari fueron de paz en el mundo andino, al parecer, por lo menos en la Costa Central. Es cuando "IRMA" se desarrolla grandemente, gracias al culto que ganaba en prestigio y a la casta sacerdotal dirigente que usufructuaba su beneficio.

Los tiempos post Wari, denominados Reynos y Confederaciones, que Pachacamac crece y se expansiona arquitectónicamente. Las edificaciones fueron apareciendo en forma espontánea por los cuatro rumbos de la ciudad, sólo teniendo cuidad que se establezcan a la vera de los cuatro caminos principales que cruzan la ciudad de Norte a Sur, de Oeste a Este y de Este a Oeste. Todas las grandes estructuras de la parte baja que son de este periodo, los consideramos "Templos Provinciales", éstos repiten monótonamente el mismo patrón constructivo, con distintas dimensiones. Aledaños a ellos hay canchones cercados, al parecer parcelas listas para ser entregados a nuevas provincias costeñas que solicitaban tener un templo en la ciudad, pues ello acrecentaba enormemente su prestigio regional. Los dirigentes del culto asegurándose que los nuevos inquilinos tengan solvencia económica como 
para mantener regularidad en la tributación, pues detrás del culto existía una verdadera organización económica, cuyos comerciantes eran los sacerdotes en exclusividad. Fue una de las cosas que Wari aportó y difundió por los Andes: el comercio organizado; mucha gente, antaño de origen Wari debe haberse arraigado en la Costa Central haciéndose pronto vecinos importantes y tomando la dirección del culto en Pachacamac. Más adelante Veremos que los cronistas españoles encuentran funcionando, pero muy disminuidos por la presencia inca, a la organización pre incaica.

Las Costa Central fue conquistada por los Incas más o menos por el año 1470, en Pachacamac hallan gente que hablan un dialecto aymaroide muy localizado; la cerámica que usaban era atípica, afectando formas y motivos decorativos imitados de los estilos Chancay, lo que hace suponer que este valle era su principal tributario y varios señores de aquella provincia deben haber tenido edificios ceremoniales en Pachacamac. El modelo arquitectónico de los edificios de este sitio se repiten mucho en Chancay, sirvan como ejemplos: Lumbra y Pisquillo Chico, sitio visitado por los autores. En el valle de Rímac, el modelo se repite con exactitud, pero en pequeñas dimensiones, en el sitio de Huaquerones III, $\mathrm{km} 8$ de la carretera central. En general todos los pueblos aledaños a Pachacamac deben haber sido tributarios, si bien no en productos y/o especias, pero sí en trabajos personal y comunal.

Los incas al llegar a posesionarse de la ciudad respetaron el templo de la antigua deidad, pero consideraron al lugar saturado de misticismo, viendo que podía utilizarse ello para servir a sus intereses; de manera que permitieron que continuara el orden anterior, pero su dirección. Edificado el Templo al Sol, la tributación se encaminaba no ya a las capillas provinciales de Pachacamac, sino a las calles construidas en las terrazas del edificio inca. Cobo dice que tenía muchos aposentos, estos deben ser los depósitos ica de los cuales salían la tributación para ir a servir en la expansión del imperio. El tempo del Sol de Pachacamac como su similar del valle de Pativilca (Paramonga) son fñabricas inca pero utilizando mano de obra costeña por eso difieren arquitectónicamente, de los edificios cuyo obraje fue quechua. Mamacuna, otro edificio Inca del estilo, sí parece haber tenido para su construcción mano de obra cuzqueña, pues paramentos líticos denuncian el estilo de cantería Cuzco, así como el ensamble sin mordiente de las piedras utilizadas. Mamacuna fue explorado, limpiado y reconstruido en un comienzo por el Dr. Julio C. Tello en 1941-42 y terminado por sus discípulos. Actualmente está cual lo dejaron sus descubridores. En el Templo del Sol nosotros hemos excavado, limpiado y consolidado la esquina Norte y el frente Oeste parcialmente, durante los años 1965-67. Así mismo, en 1963, el Dr. Arturo Jiménez Borja exploró y limpió un sector de la verdadera escalera de acceso al edificio; esta es en zigzag con descansos, y los muros que la enmarcan muy pintados con amarillo y rojo. El mismo Dr. Jiménez Borja había trabajado desde 1958 hasta 1962, uno de los edificios provinciales de la parte bajan que fue bautizado por Hans Horkheimmer como "JB" por su peculio trataba de hacer arqueología en este sitio a la sazón ya cuasi abandonado.

Durante la segunda mitad del año 1967 y todo 1968 hemos excavado y limpiado el palacio de Tauri Chumbi curaca orejón que gobernaba políticamente Pachacamac a la llegada de los españoles, los materiales están en estudio y serán publicados oportunamente, Este edificio lo denominamos Grupo Tauri Chumbi ahora todavía no puede ser visitado porque falta trabajo, en la misma situación está el Grupo "JB". Para sintetizar todo lo dicho, arquitectónica de los edificios, así como de su ubicación cultural:

$$
\begin{aligned}
& \text { Arquitectura Inca: } \\
& \text { - Templo del Sol } \\
& \text { - Mamacuna } \\
& \text { - Plaza de los Peregrinos } \\
& \text { - Grupo Tauri Chumbi } \\
& \text { - Edificio pintado }
\end{aligned}
$$

Arquitectura Pre Inca:

-E)Calles: Norte-Sur; Oeste-Este; EsteOeste

-D) Templo de Pachacamac

-C) Palacios periféricos

-B)Capillas provinciales

-A)Edificios Maranha:

o Urpi Wachak

o Cercanías de Mamacuna

o Templete adobitos 
Los edificios mayores son el templo Pre Inca de Pachacamac y el templo Inca del Sol.

Mamacuna estuvo rodeado de sembríos en la antigüedad, que eran parcelas del Sol y Tello puso en evidencia una serie de canales servidos por napa freática, para almacenarla en reservorios de piedra.

A continuación presentamos un estudio a base de crónicas, que son testimonios algunos directos y otros indirectos de lo que los españoles pudieron aprehender en Pachacamac.

stando preso en Cajamarca el Príncipe Atahualpa ofrece a sus captores como precio por su vida dos estancias casi colmadas de oro y plata. Aceptado el rescate comienzan a llegar tesoros desgajados de templos y palacios. Muchas de las piezas eran de tamaño temerario y demandaban tiempo y esfuerzo para su transporte. Conocedor de la prisa que tenían los conquistadores porque tal riqueza se reúna, Atahualpa sugiere se recoja de los bienes que atesora Pachacamac. Era este un lugar famoso asiento de una antigua deidad del mismo nombre venerada por las naciones que habitaban los llanos a la orilla del mar. Francisco Pizarro se sorprende cómo siendo tan gran dios este Pachacamac se le iba a quitar lo suyo. Atahualpa responde con agudeza notable. Testigo del diálogo es un paje y pariente del Gobernador, quien años más tarde sería el cronista Pedro Pizarro. En su vejez recuerda este episodio y lo trasmite en su crónica "Relación del Descubrimiento y Conquista del Perú": "Has de saber señor, dijo Atahualpa, que estando mi padre malo en Quito, le envió a preguntar que haría para su salud; dijo que lo sacasen al sol, y en sacándole murió, Huascar mi hermano le envió a preguntar quién había de vencer, y dijo que él, y vencí yo; cuando vosotros vinisteis yo le envié a preguntar quien había de vencer, vosotros y yo, enviome a decir que yo y vencisteis vosotros. Así que es mentiroso y no Dios, pues miente".

Pachacamac es un nombre quechua. Quiere decir Dios Creador. Según el Vocabulario de 1608 compuesto por Diego Gonzales de Holguín la palabra Pacha equivale a decir: tiempo o lugar y Camac Dios Creador. Considerando que la conquista del litoral central fue acome- tida por los Incas en el siglo XV, resulta entonces el nombre Pachacamac relativamente reciente. Su nombre arcaico debe haber sido Irma. Según la Relación Origen, Descendencia Política y Gobierno de los Incas, escrito por el licenciado Fernando Santillán, estando en gestación Topa Inca habló en el vientre de su madre diciendo: "que el Hacedor de la tierra estaba en los yungas, en el valle de Irma". El cronista aclara "dicho valle de Irma que agora se llama Pachamama" o sea el actual valle del río Lurín en una de cuyas márgenes están las ruinas del templo dedicado al Dios Pachacamac. Lo dicho concuerda con el nombre de un lugar próximo llamado Arma Tambo. Quizá en la antigüedad se le conoció como Irma Tambo; vale decir Tambo o Parador del Dios Irma. Aun hoy es posible ver allí importantes construcciones prehispánicas. Un nombre aun más antiguo pudo haber sido Kon. El padre Ávila gran extirpador de idolatrías informa de un dios muy venerado en las altas montañas de Yauyos y Huarochirí en el siglo XVII, llamado Con Iraya. Francisco López de Gómara trae una importante noticia acerca de lo mismo. Aparece en la primera parte de la "Historia General de las Indias" e el capítulo "Opinión que tiene acerca del diluvio y primeros hombres". Allí se puede leer "Dice que a los comienzos del mundo vino de la parte septentrional un hombre que se llamó Con, el cual no tenía huesos" (referencia metafórica a cu condición de espíritu). Prosigue Gómara: "llenó la tierra de hombres y mujeres que crió". "Pero sin embargo, enojado por lo que algo no le hicieron, volvió la buena tierra que les había dado en arenales secos y estériles, como son las de la costa y les quitó la lluvia, pues nunca más desde entonces volvió a llover allî". Aparece entonces en el relato, en forma dramática, el Dios Pachacamac. "Sobreviene Pachacamac que significa creador y desterró a Con”. El mito describe muy bien el teatro de los acontecimientos, arenales secos y estériles, y pone en evidencia el orden de aparición de las divinas personas.

Reinando el Emperador Topa Inca Yupanqui (1471-1494) lleva a cabo la conquista del litoral y Pachacamac pasó a formar parte del Estado Inca. Los conquistadores españoles llegaron a Lima en 1533. El tiempo entre una y otra ocupación no es grande, por tanto el gobierno Inca no pudo cambiar gran cosa la fisonomía 
de Pachacamac. El grueso de los edificios que los conquistadores vieron eran de origen preinca, siendo los edificios incas más sobresalientes, el Templo dedicado al Sol y otra fábrica en dónde funcionaba la institución femenina llamada Mamacuna. Tan grandes instalaciones, como hasta ahora se ve, tomaron del gobierno Inca gran importancia de su tiempo.

Volviendo al principio del nuestra historia, el Gobernador ordenó a su hermano Hernando se encamine hacia Pachacamac en procura de cuanto atesoraba la ciudad sagrada. Pizarro advierte por el camino que la tributación de los valles marítimos la recaudaba Pachacamac: "toda esta tierra de los llanos y más adelante no tributa al Cuzco, sino a la mezquita" dice en carta escrita a los oidores de Santo Domingo.

La tributación en el antiguo Perú era compleja. Se tributaba, en general, aquello que más abundaba en el lugar. Materias primas como maíz, sal, algodón, tinturas, etc.; manufacturas como ovillos de algodón hilado, mantas, ropa, etc.; mano de obra como olleros, carpinteros, músicos, etc. La tributación por excepción era oro y plata. Todos estos valores se atesoraban en Pachacamac de modo tal que el sitio venía a ser una suerte de Banco de las Naciones que vivían en los llanos. Los valores que se guardaban en este repositorio no coincidían, como es natural, con la idea que los valores tenían los conquistadores españoles. El cuerpo sacerdotal componía un cuadro subalternos y ejecutivos encargado de llevar cuentas de lo atesorado y de cuanto salía de los depósitos en beneficio del pueblo o del culto de Dios.

El cronista Miguel de Estete que acompañó a Hernando Pizarro desde Cajamarca a Lima y que vio a Pachacamac funcionando bajo la administración Inca, recoge esta impresión: "Debe ser cosa muy antigua, porque hay edificios caídos y han sido cercados el pueblo, aunque al presente lo más de la cerca está caída". Este deterioro, correspondía probablemente al antiguo sector preinca, cuyo esplendor había declinado hacía años, en beneficio del nuevo culto solar y las instituciones incas. Los trabajos arqueológicos han puesto en valor esta observación de Estete, pues se ha hallado edificios preincas que estuvieron dedicados al culto transformados en basureros. Como muchos de ellos no tenían ninguna función religiosa que cumplir, pues el ceremonial tenían ahora otros escenarios; fueron entonces lentamente abandonados y se acumuló allí gran cantidad de desechos de la población inca.

Miguel de Estete refiere también que los indígenas le información acerca de las funciones del dios Pachacamac expresando, que "los cría y sostiene" y "que les puede hundir si le enojan". Como los griegos y muchos otros pueblos de la antigüedad, los peruanos se imaginaban quizá que el mundo era plano y sostenido por los lomos de la deidad. Esta creencia hall justa expresión al decir los indígenas "que les puede hundir si se le enojan", pues se entiende que de faltar el principio se sustentación el mundo se había de hundir y siendo la costa tierra de temblores, abona a favor de lo dicho. Corrobora todo esto, un acontecimiento que sucede a Hernando Pizarro y a los suyos a las puertas del templo de Pachacamac. Lo refiere Miguel de Estete "Acaecionos una cosa muy donosa, una noche antes que llegáramos a él en un pueblo junto a la mar, que nos tembló la tierra de un recio temblor y los indios que llevábamos que muchos de ellos iban tras nosotros a vernos, huyeron aquella noche de miedo diciendo que Pachacamac se enojaba porque íbamos allá y todos habíamos de ser destruidos". A través de estos testimonios es fácil advertir el diseño majestuoso de la divinidad sustentadora del mundo antiguo y como la buena marcha de las cosas de la tierra dependían de la quietud y bondad de Dios.

Antes que los Incas conquistaran el litoral, el tributo estaba dirigido al Dios Pachacamac. El cuerpo sacerdotal adscrito a él lo recibía y administraba, De cada cantón costeño partía probablemente, según su tiempo, el curaca local acompañado de una corte de servidores con ofrendas que se almacenaban en "casas de depósito" como los llama Estete y Hernando Pizarro. Estas casas eran en cierto modo templos provinciales. En Pachacamac los hay de muchas clases, mas todas ellas muy parecidas. Constan de un gran patio delantero o atrium luego un edificio en forma de pirámide trunca en cuyo tope hay unas pocas cámaras sagradas. Rampas muy ceremoniosas permiten ascender a la pirámide. Tras todo esto, enormes depósitos. Mirando uno de estos edificios, con 
los ojos del espíritu, se puede volver a revivir el pasado. Es posible ver a los curacas locales, acompañados por músicos, bailarines y portadores, presentar los tributos en los grandes patios y sacerdotes desde lo alto de las pirámides, dando majestuosamente su aceptación. Este tributo bendecido y grato era entregado a los servidores del templo que lo guardaban y contabilizaban.

Cada uno de estos templos provinciales recibía ofrendas de una comunidad muy señalada, Año a año recibía casi siempre lo mismo: algodón, maíz, pescado, etc aquello que más abundaba en la localidad. Era un rubro conocido y sobre la base de él giraban las operaciones del templo. Al llegar la época de recolección, cada unidad-templo almacenaba un repertorio monótono. Más considerando la ciudad en conjunto con sus muchos templos-almacenes, la diversidad era muy grande. Probablemente cada grupo sacerdotal realizaba operaciones para diversificar su riqueza trocando lo que tenía en abundancia por aquello que le faltaba. Quizá esperaba que llegasen a su templo devotos o tratantes a solicitar aquello que sabían constituía la especialidad del templo. En suma la ciudad recibía una riqueza que sin duda no quedaba estática, sino que circulaba y se transformaba. Esta complicada dinámica estaba dirigida por el cuerpo sacerdotal. Así las cosas la ciudad no era sólo un centro religioso, sede del Dios Pachacamac, sino también un emporio de riqueza, de valores que acrecentaba su prestigio y su poder. Con la llegada de los Incas cambia el rumbo de los tributos. Ahora en lugar de henchir los depósitos del gran Dios Pachacamac y de sus servidores. El grueso de ellos se dirige al templo del Sol y a los almacenes de las instituciones Incas. La vieja maquinaria Pre-Inca vendrá a menos poco a poco y los funcionarios de Pachacamac se transforman en pobres vergonzantes. No obstante el Dios sigue en funciones, Huayna Capac le pregunta sobre sus males, el Inca Huascar le pide opinión sobre su suerte en la guerra con su hermano y Atahualpa pide también consejo. Y, sin embargo, ya se duda mucho de él y se le llama mentiroso descaradamente. Y el gran Dios, como si estuviese resentido, de respuestas contrarias, una y otra vez, como silo hiciera de intento.
La crónica "Historia General y natural de las Indias" escrita por Gonzáles Fernández de Oviedo escribe, en el capítulo X del tomo V, la vida del príncipe Atahualpa en prisión: "Sabía por los caciques e señores de aquellas provincias la ida del gobernador a Caxamalca e la presión de Atabaliba, muchos e de diversos pueblos vinieron e algunos aún desde bién lejos a ver al gobernador, de paces e algunos dellos eran señores de a veinte a treinta mil indios, e todos subjetos a Atabaliba la hacían grandísimo acatamiento, besándole los pies e las manos y él los recibía sin alzar los ojos aún a mirarlos, porque su gravedad o grandeza deste príncipe era muy grande e la obediencia de sus súbditos conforme a ella, e cada día le traían muchos presentes de la tierra". iAsí mismo, pasados sesenta días después de la prisión de Atabaliba, llegó un cacique del pueblo donde está aquella mezquita general de Pachamama, y el guardián Della. E llegados ante el gobernador, preguntó a Atabaliba quién eran. e dijo que se holgaba con su venida, porque pagarán las mentiras que le habían dicho; e pidió que le trajesen allí una cadena para echársela a aquél guardián, porque era un bellaco mentiroso que le había dicho e acnsejado que tuviese guerra con los cristianos, que su dios le había dicho que los mataría a todos, e que también dijo a su padre Guainacaba, cuando se quiso morir, que no moriría de aquella enfermedad, certificando que su dios lo decía". El gobernador mandó traer la cadena a Atabaliba se la echó al guardián e dijo que no se la quitase hasta que trajese todo el oro que tenía en el dicho templo o mezquita para los españoles. E dijo Atabaliba que él lo quería dar a los cristianos, pues su dios de aquel mal sacerdote era mentiroso, e dijo así; Yo quiero ver agora tu saber, e como tu dios te quita desa cadena".

Hernando Pizarro se hallaba por aquel tiempo en Huanachuco, Allí recibe orden de encaminarse a Pachacamac. Un hidalgo llamado Miguel de Estete fue encargado de relatar el viaje. Desde Huamachuco se encaminan a través de las altas montañas hacia el sur, luego desviándose del camino real descienden al encuentro del camino de los llanos, junto al mar. Según Estete partieron de Cajamarca un miércoles 6 de enero de 1533 y llegaron a Pachacamac el 30 de enero del mismo año. AL entrar en la ciudad sagrada el día al parecer 
declinaba, pues poco antes habían comido en Armatambo a las afueras de la actual ciudad de Chorrillos. No bien llegaron a Pachacamac, según Estete, "se fueron a aposentar a unos aposentos grandes que están a una parte de dicho pueblos". Refiere luego cómo Hernando Pizarro comunicó al principal del pueblo llamado Tauri Chumbi "que el iba por mandato del señor gobernador por el oro que el cacique y obispo de aquella mezquita había mandado al dicho gobernador, e que luego a la hora lo juntasen e se lo diesen" "E juntos todos los señores del pueblo e principales e pajes de aquel ídolo que allí tenían dijeron que lo darían, e andovieron disimulando e dilatando: en conclusión que trajeron muy poco y dijeron que no había más".

Pachacamac era un grandioso repositorio. Hasta hoy quedan los inmensos depósitos, distribuidos por doquier, en número y tamaño verdaderamente abrumador. Por tanto llama la atención la conducta de principales y sacerdotes, que tras dilatar la entrega trajeron poco y dijeron que no había más. Es probable que a lo largo de los veinticuatro días de viaje de Hernando Pizarro llegaron a Lima noticias de las intenciones de los españoles. Quizá el sumo sacerdote humillado y encadenado en Cajamarca ordenaría la conducta a seguir.

Estete menciona unas "casas donde se echaba el tributo". Estos edificios, qua aún están en pie, los hemos llamado tentativamente "templos provinciales". La limpieza de uno de ellos ha proporcionado una idea más o menos clara de cómo eran los demás, que sólo se diferencian en proporciones. Estete dice que en estos edificios "se halló algún oro y muestras de haber alzado mucha cantidad dello".

El viaje de Hernando Pizarro a la ciudad sagrada hubiese resultado un fracaso de no mediar un notable acontecimiento. Poco a poco comenzaron a llegar a Pachacamac señores y príncipes del contorno. Presentaban su obediencia y con ella, conforme a la etiqueta, regalos de oro y plata. La lista de señores, poco firme en sus convicciones la ha transmitido Miguel de Estete. Estos son: Lincoto, señor de Mala; Allaucax, señor de Noax; Guaralla, señor de Huayco; Guagchapaicho, señor de Huarca; Ispillo, señor de Sulliscasmarca, y por último Chumbiauca, señor de Chincha que se presentó con un brillante cortejo de diez caballeros principales.

No puede quedar sin un comentario postrero la valerosa conducta de los sacerdotes y señores de Pachacamac. Se necesitó gran entereza para presentarse ante los españoles con las manos vacías.

Se necesitó también valor grande para vaciar los depósitos de la deidad y del pueblo, y destruir u ocultar lo atesorado y desmantelar los templos.

Sin duda alguna, la realización de esta formidable tarea debió tomarlos muchos días de trabajo y dolor inmensos. 